\section{Original Article}

Korean J Transplant 2022;36:45-53 https://doi.org/10.4285/kjt.21.0031
Received December 8, 2021

Revised January 20, 2022

Accepted February 8, 2022

Corresponding author: Shin Hwang Department of Surgery, Asan Medical Center, University of Ulsan College of Medicine, 88 Olympic-ro 43-gil, Songpagu, Seoul 05505, Korea

Tel: +82-2-3010-3930

Fax: +82-2-3010-6701

E-mail: shwang@amc.seoul.kr

(c) The Korean Society for Transplantation This is an Open Access article distributed under the terms of the Creative Commons Attribution Non-Commercial License (http://creativecommons.org/licenses/ by-nc/4.0/) which permits unrestricted non-commercial use, distribution, and reproduction in any medium, provided the original work is properly cited.

\section{$\mathrm{KJT}^{\mathrm{K}}$ \\ KOREAN JOURNAL OF TRANSPLANTATION}

pISSN 2671-8790

eISSN 2671-8804

\title{
Twenty-year longitudinal follow-up after liver transplantation: a single-center experience with 251 consecutive patients
}

Minjae Kim, Shin Hwang, Chul-Soo Ahn, Deok-Bog Moon, Tae-Yong Ha, Gi-Won Song, Dong-Hwan Jung, Gil-Chun Park, Ki-Hun Kim, Jung-Man Namgoong, Woo-Hyoung Kang, Young-In Yoon, Hwui-Dong Cho, Byeong-Gon Na, Sang Hoon Kim, Sung-Gyu Lee

Division of Hepatobiliary Surgery and Liver Transplantation, Department of Surgery, Asan Medical Center, University of Ulsan College of Medicine, Seoul, Korea

Background: The outcomes of liver transplantation (LT) have improved, but actual 20year survival data have rarely been presented.

Methods: Longitudinal follow-up data of 20-year LT survivors were retrospectively analyzed. The LT database of our institution was searched to identify patients who underwent primary LT from January 2000 to December 2001. The study cohort of 251 patients was divided into three groups: 207 adults who underwent living donor LT (LDLT), 22 adults who underwent deceased donor LT (DDLT), and 22 pediatric patients who underwent LT.

Results: Hepatitis B virus-associated liver cirrhosis and biliary atresia were the most common indications for adult and pediatric $L T$, respectively. Seven patients required retransplantation, including six who underwent DDLT and one who underwent LDLT. Twenty-two patients died within 3 months after LT and 69 died at later intervals. The overall survival rates at $1,3,5,10$, and 20 years were $86.4 \%, 79.6 \%, 77.7 \%, 72.8 \%$, and $62.6 \%$, respectively, in the adult LDLT group; $86.4 \%, 72.7 \%, 72.7 \%, 72.7 \%$, and $68.2 \%$, respectively, in the adult DDLT group; and $86.4 \%, 86.4 \%, 81.8 \%, 81.8 \%$, and $77.3 \%$, respectively, in the pediatric LT group $(\mathrm{P}=0.545)$. Common immunosuppressive regimens at 20 years included tacrolimus monotherapy, tacrolimus-mycophenolate dual therapy, cyclosporine monotherapy, and mycophenolate monotherapy.

Conclusions: The present study is the first report of actual 20-year survival data from a Korean high-volume LT center. The graft and patient survival outcomes reflected the early experiences of LT in our institution, with long-term outcomes being similar regardless of graft type and patient age.

Keywords: Living donor; Deceased donor; Donor shortage; Long-term follow-up; Perioperative mortality 


\section{HIGHLIGHTS}

- A study cohort of 251 liver transplantation (LT) recipients were followed up for 20 years.

- The actual 20 -year patient survival rate was $62.6 \%$ in 207 adult living donor LT recipients, $68.2 \%$ in 22 adult deceased donor LT recipients, and $77.3 \%$ in 22 pediatric LT recipients.

- These survival outcomes reflected the early experiences of LT in our institution, with long-term outcomes being similar regardless of graft type and patient age.

\section{INTRODUCTION}

Liver transplantation (LT) prolongs survival and improves quality of life in patients with liver diseases that are not effectively treated by other modalities. Over the past two decades, the long-term outcomes of LT have improved worldwide. The European [1] and American [2] Liver Transplant Registries have reported 10-year survival rates of over $60 \%$ each. Less is known, however, about actual 20 year survival data and immunosuppressive regimens in Korea [3-5]. There have been remarkable developments in LT in Korea during the last 20 years, including the introduction of many innovative surgical techniques, especially regarding living donor LT (LDLT), the more frequent performance of deceased donor LT (DDLT), and improvements in immunosuppressive regimens [6-9]. The present study retrospectively analyzed the clinical outcomes and immunosuppressive regimens of LT survivors who have been followed up for 20 years.

\section{METHODS}

The study protocol was approved by the Institutional Review Board of Asan Medical Center (IRB No. 2021-0857), which waived the requirement for informed consent due to the retrospective nature of this study. This study was performed in accordance with the ethical guidelines of the World Medical Association Declaration of Helsinki 2013.

\section{Patients}

The primary endpoint of this study was actual 20-year posttransplant survival. The secondary endpoint was the immunosuppressive regimen at 20 years after LT. Thus, longitudinal follow-up data were retrospectively analyzed in 20-year LT survivors. The LT database of our institution was searched to identify patients who underwent primary LT from January 2000 to December 2001. Selected patients were divided into three groups based on graft type and recipient age; adult LDLT, adult DDLT, and pediatric LT (with pediatric patients defined as recipients aged less than 18 years). Clinical follow-up information of these patients was cross-sectionally collected during a 1-month period in August 2021. All patients were followed up until August 2021 or patient death. Institutional medical records were reviewed to determine graft and patient survival, and the database of the National Health Insurance Service of Korea was reviewed to confirm patient survival. The immunosuppressive agent dosage and trough level used for analysis were those recorded from alive patients at their most recent outpatient follow-up visit.

\section{Statistical Analysis}

Numerical data are presented as mean \pm standard deviation or median with range. Continuous variables were compared using the Student t-test. Incidence variables were compared using the chi-square test or the Fisher's exact test. Survival rates were estimated using the Kaplan-Meier method and compared using the log-rank test. A P-value $<0.05$ was considered to indicate statistical significance. All statistical analyses were performed using IBM SPSS ver. 22 (IBM Corp., Armonk, NY, USA).

\section{RESULTS}

\section{Patient Profiles}

The study cohort consisted of 251 patients who underwent primary LT from January 2000 to December 2001. This cohort was divided into three groups, consisting of 207 patients who underwent adult LDLT, 22 who underwent adult DDLT, and 22 who underwent pediatric LT. The most common primary indications for LT were hepatitis B virus (HBV)-associated liver cirrhosis $(n=177,85.5 \%)$ and fulminant hepatic failure $(n=14.6 .8 \%)$ in the adult LDLT group; HBV-associated liver cirrhosis $(n=20,90.9 \%)$ in the adult DDLT group; and biliary atresia $(n=16,72.7 \%)$ in the pediatric LT group. The profiles of patients belonging to these three groups are summarized in Table 1. Patient age, pretransplant laboratory profiles, and model for end-stage 
Kim $\mathrm{M}$ et al. Twenty-year survival after liver transplantation

Table 1. Demographic and clinical characteristics of patients in the adult LDLT, adult DDLT, and pediatric LT groups

\begin{tabular}{|c|c|c|c|c|}
\hline Variable & Adult LDLT & Adult DDLT & Pediatric LT & $\begin{array}{c}\text { P-value } \\
\text { (adult LDLT vs. DDLT) }\end{array}$ \\
\hline No. of patients & 207 & 22 & 22 & \\
\hline Recipient (male:female) & 169:38 & $15: 7$ & $7: 15$ & 0.741 \\
\hline Recipient age (yr) & $46.2 \pm 8.3$ & $44.4 \pm 9.9$ & $2.2 \pm 3.2$ & 0.236 \\
\hline Primary disease & & & & $0.483^{\mathrm{a})}$ \\
\hline HBV-LC & $177(85.5)$ & $20(90.9)$ & & \\
\hline ALF & $14(6.8)$ & & $3(13.6)$ & \\
\hline HCV-LC & $6(2.9)$ & & & \\
\hline ALD & $4(1.9)$ & & & \\
\hline Cryptogenic LC & $2(1.0)$ & $1(4.5)$ & & \\
\hline Wilson disease & $2(1.0)$ & & & \\
\hline PSC & $1(0.5)$ & $1(4.5)$ & & \\
\hline SBC & $1(0.5)$ & & & \\
\hline BA & & & $16(72.7)$ & \\
\hline Metabolic disease & & & $3(13.6)$ & \\
\hline \multicolumn{5}{|l|}{ Preoperative laboratory finding } \\
\hline Total bilirubin (mg/dL) & $10.6 \pm 13.8$ & $7.4 \pm 7.6$ & $15.4 \pm 14.7$ & 0.276 \\
\hline Serum creatinine (mg/dL) & $1.09 \pm 0.91$ & $0.91 \pm 0.21$ & $0.61 \pm 0.97$ & 0.351 \\
\hline Prothrombin time (INR) & $2.39 \pm 1.32$ & $2.03 \pm 0.78$ & $1.51 \pm 0.45$ & 0.223 \\
\hline Platelet count $\left(\times 10^{3} / \mathrm{mL}\right)$ & $61.8 \pm 44.1$ & $44.1 \pm 27.7$ & $160.7 \pm 81.3$ & 0.067 \\
\hline MELD/PELD score & $25.5 \pm 10.8$ & $24.6 \pm 9.6$ & $12.1 \pm 4.7$ & 0.693 \\
\hline $\mathrm{HCC}$ at explant liver & $48(23.2)$ & $3(13.6)$ & 0 & 0.569 \\
\hline Donor sex (male:female) & $171: 36^{\mathrm{b})}$ & $15: 7$ & $8: 14$ & 0.099 \\
\hline Donor age (yr) & $27.1 \pm 7.3$ & $23.4 \pm 10.4$ & $30.7 \pm 5.2$ & 0.036 \\
\hline \multicolumn{5}{|l|}{ Graft type (n) } \\
\hline Whole liver & & $21(95.5)$ & $1(4.5)$ & \\
\hline Right liver & $158(76.3)$ & $1(4.5)$ & & \\
\hline Left liver & $29(14.0)$ & & $12(54.5)$ & \\
\hline Left lateral section & & & $9(40.9)$ & \\
\hline Dual-graft & $20(9.7)$ & & & \\
\hline Graft weight (g) & $669.3 \pm 148.1$ & $1215.3 \pm 271.6$ & $272.5 \pm 83.1$ & $<0.001$ \\
\hline Graft-recipient weight ratio & $1.01 \pm 0.25$ & $1.76 \pm 0.34$ & $2.61 \pm 0.65$ & $<0.001$ \\
\hline \multicolumn{5}{|l|}{ Ischemic time (min) } \\
\hline Cold & $75.5 \pm 86.4$ & $352.6 \pm 208.9$ & $27.1 \pm 24.7$ & $<0.001$ \\
\hline Warm & $52.1 \pm 110.5$ & $138.6 \pm 128.8$ & $31.2 \pm 13.6$ & $<0.001$ \\
\hline
\end{tabular}

Values are presented as mean \pm standard deviation or number (\%).

LDLT, living donor liver transplantation; DDLT, deceased donor liver transplantation; HBV, hepatitis B virus; LC, liver cirrhosis; ALF, acute liver failure; HCV, hepatitis $C$ virus; ALD, alcoholic liver disease; PSC, primary sclerosing cholangitis; SBC, secondary biliary cirrhosis; BA, biliary atresia; INR, international normalized ratio; MELD, model for end-stage liver disease; PELD, pediatric end-stage liver disease; HCC, hepatocellular carcinoma.

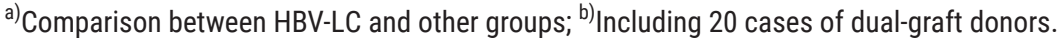

liver disease (MELD) scores were similar in the adult LDLT and DDLT groups.

Only one adult patient underwent split LT, whereas no patients did so in the pediatric LT group. The graft-to-recip- ient weight ratios in the adult LDLT and DDLT groups were $1.01 \pm 0.25$ and $1.76 \pm 0.34$, respectively $(P<0.001)$. Cold and warm ischemic times were significantly longer in the adult DDLT group than in the adult LDLT group ( $\mathrm{P}<0.001$ each). 
A

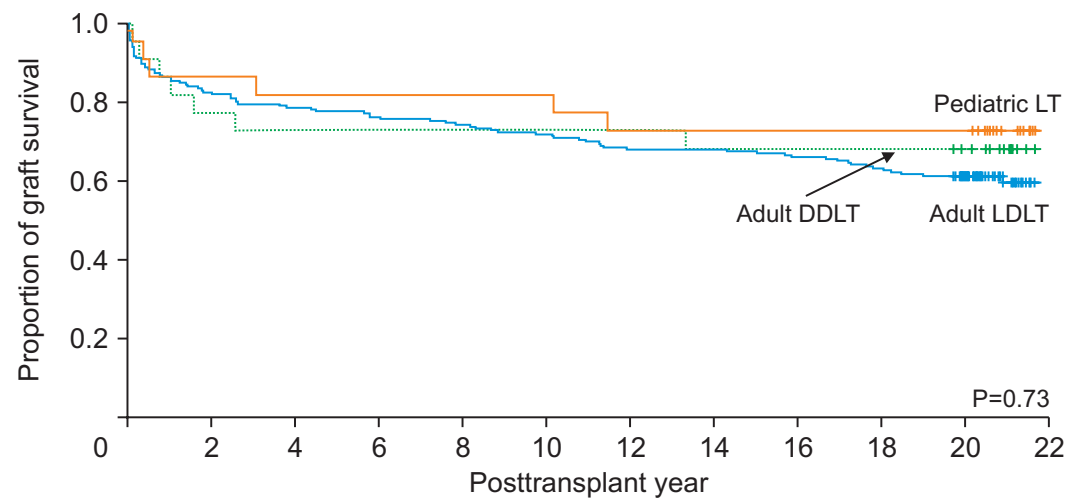

\begin{tabular}{|r|r|r|r|r|r|r|r|r|r|r|r|r|}
\hline Patients at risk & & & & & & & & & & & & \\
\hline Adult LDLT & 207 & 169 & 162 & 157 & 153 & 148 & 142 & 140 & 136 & 130 & 98 & 0 \\
\hline Adult DDLT & 22 & 17 & 16 & 16 & 16 & 16 & 15 & 15 & 15 & 15 & 12 & 0 \\
\hline Pediatric LT & 22 & 19 & 18 & 18 & 19 & 18 & 17 & 16 & 16 & 16 & 16 & 0 \\
\hline
\end{tabular}

B

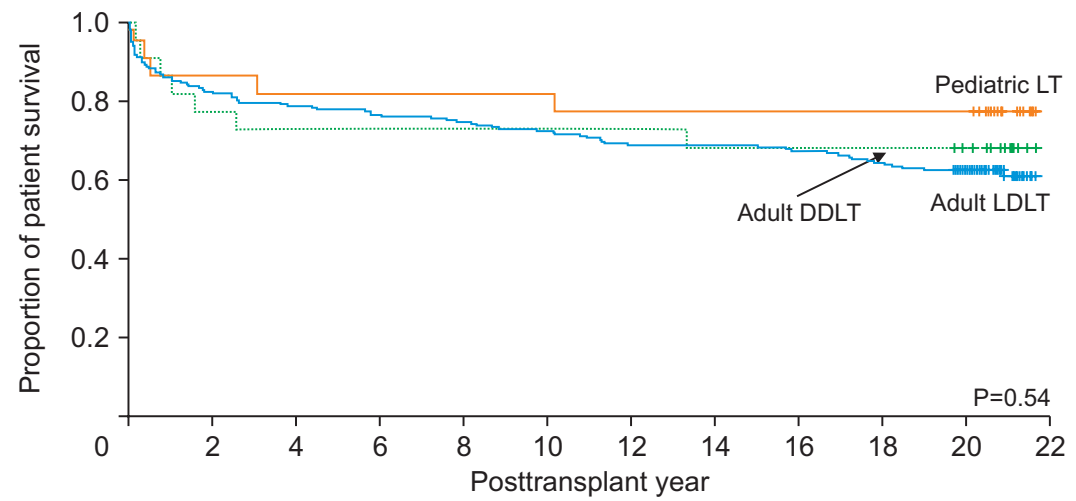

\begin{tabular}{|r|r|r|r|r|r|r|r|r|r|r|r|r|}
\hline Patients at risk & & & & & & & & & & & & \\
\hline Adult LDLT & 207 & 169 & 162 & 157 & 153 & 150 & 142 & 142 & 139 & 133 & 101 & 0 \\
\hline Adult DDLT & 22 & 17 & 16 & 16 & 16 & 16 & 15 & 15 & 15 & 15 & 12 & 0 \\
\hline Pediatric LT & 22 & 19 & 18 & 18 & 19 & 18 & 17 & 17 & 17 & 17 & 17 & 0 \\
\hline
\end{tabular}

Fig. 1. Kaplan-Meier analysis of graft (A) and patient (B) survival curves stratified by graft type and patient age. LT, liver transplantation; DDLT, deceased donor liver transplantation; LDLT, living donor liver transplantation.

\section{Posttransplant Graft Survival}

The graft survival rates at 3 months and at $1,3,5,10$, and 20 years were $91.3 \%, 86.4 \%, 79.6 \%, 77.7 \%, 71.9 \%$, and $61.2 \%$, respectively, in the adult LDLT group; $95.5 \%, 86.4 \%$, $72.7 \%, 72.7 \%, 72.7 \%$, and $68.2 \%$, respectively, in the adult DDLT group; and $100 \%, 86.4 \%, 86.4 \%, 81.8 \%, 81.8 \%$, and $72.7 \%$, respectively, in the pediatric group $(\mathrm{P}=0.732)$ (Fig. 1).

Retransplantation was performed in seven patients. One DDLT recipient underwent a second DDLT 1 month later due to early allograft dysfunction. Five LDLT recipients underwent DDLT, one due to a biliary complication at 21 months, one due to outflow vein obstruction at 104 months, one due to chronic rejection at 117 months, one due to portal vein thrombosis at 122 months, and one due to liver cirrhosis of unknown cause at 172 months. One pediatric LT recipient underwent LDLT due to graft outflow vein obstruction at 137 months. Of these seven patients, three died within 3 months after retransplantation, and the other four survived for more than 5 years.

\section{Posttransplant Overall Survival}

The patient survival rates at 3 months and at $1,3,5,10$, and 20 years were $91.3 \%, 86.4 \%, 79.6 \%, 77.7 \%, 72.8 \%$, and $62.6 \%$, respectively, in the adult LDLT group; $95.5 \%, 86.4 \%$, $72.7 \%, 72.7 \%, 72.7 \%$, and $68.2 \%$, respectively, in the adult DDLT group; and $100 \%, 86.4 \%, 86.4 \%, 81.8 \%, 81.8 \%$, and $77.3 \%$, respectively, in the pediatric group ( $\mathrm{P}=0.545)$ (Fig. 2).

Patients' deaths were divided into perioperative mortality within 3 months after $L T(n=22)$ and late mortality $(n=69)$. The causes of perioperative mortality included 
A

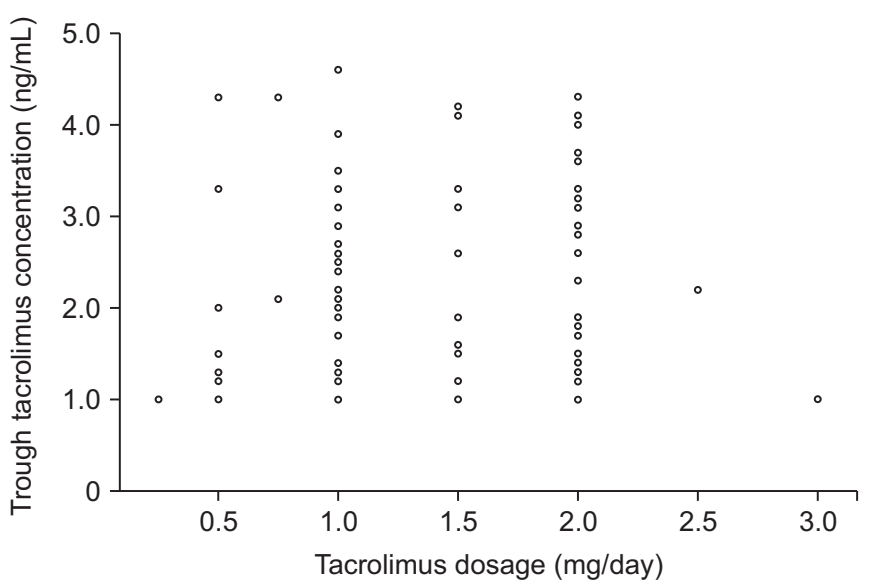

B

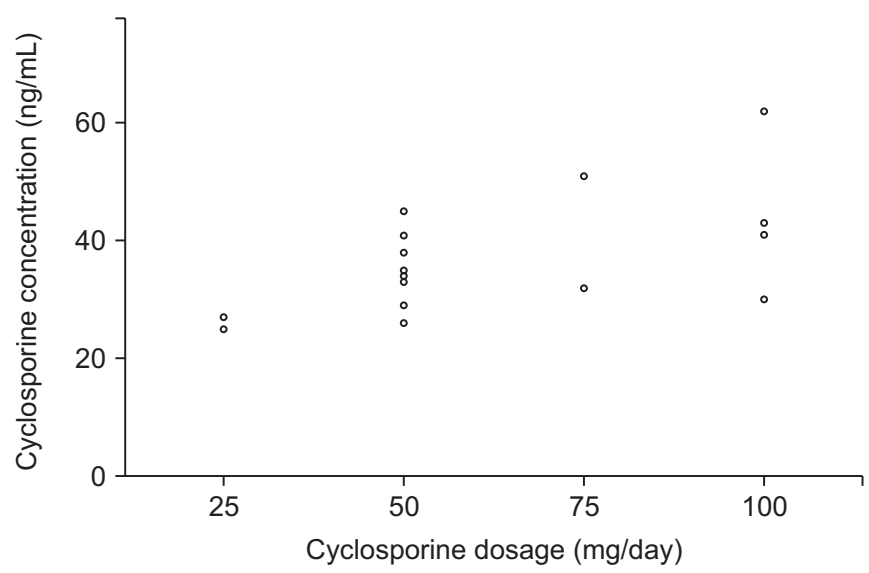

Fig. 2. Relationship between the daily dosage of immunosuppressants and their trough concentration in liver transplant recipients who were administered tacrolimus (A) or cyclosporine (B) monotherapy.

primary graft nonfunction and early allograft dysfunction, bleeding, infection, and vascular and biliary complications. The causes of late mortality included pneumonia $(n=18)$, chronic rejection and graft failure $(n=11)$, recurrence of hepatocellular carcinoma (HCC; $n=5)$, de novo malignancy $(n=5)$, cerebrovascular accident $(n=5)$, ischemic cardiac disease $(n=3)$, HBV recurrence $(n=3)$, hepatitis $C$ virus recurrence $(n=3)$, renal failure $(n=1)$, biliary complication $(n=1)$, abdominal infection $(n=1)$, and unknown cause $(n=10)$.

\section{Immunosuppressive Regimens at $\mathbf{2 0}$ Years after LT}

The immunosuppressive regimens in 160 alive recipients included tacrolimus (FK) monotherapy in 92 (57.9\%); dual therapy with FK and mycophenolate mofetil (MMF) in 25 $(15.7 \%)$; triple therapy with FK, MMF and everolimus in 1 $(0.6 \%)$; dual therapy with FK and everolimus in $3(1.9 \%)$; cyclosporine monotherapy in $18(11.3 \%)$; dual therapy with cyclosporine and MMF in $1(0.6 \%)$; MMF monotherapy in $18(11.3 \%)$; and everolimus monotherapy in $1(0.6 \%)$. Of the 121 patients receiving $\mathrm{FK}, 16$ (13.2\%) were treated with prolonged-release FK (Advagraf; Astellas Pharma Inc., Tokyo, Japan).

The median and mean daily dosages of FK in the 92 recipients receiving FK monotherapy were $1.0 \mathrm{mg} /$ day (range, $0.25-3.0 \mathrm{mg} / \mathrm{day}$ ) and $1.35 \pm 0.59 \mathrm{mg} /$ day, respectively; and their median and mean trough FK concentrations were $2.0 \mathrm{ng} / \mathrm{mL}$ (range, $1.0-4.6 \mathrm{ng} / \mathrm{mL}$ ) and $2.22 \pm 1.06 \mathrm{ng} / \mathrm{mL}$, respectively (Fig. $2 \mathrm{~A}$ ). The median and mean daily dosage of cyclosporine in the 18 recipients who were administered cyclosporine monotherapy were $50 \mathrm{mg} /$ day (range, 25-100 $\mathrm{mg} /$ day) and $59.7 \pm 25.9 \mathrm{mg} /$ day, respectively; and their median and mean trough cyclosporine concentrations were $33 \mathrm{ng} / \mathrm{mL}$ (range, 25-62 ng/mL) and $35.9 \pm 9.9 \mathrm{ng} / \mathrm{mL}$, respectively (Fig. 2B).

\section{DISCUSSION}

Aside from a brief report regarding initial LT experiences in our institution [4], the present study is the first report of actual 20-year survival data at a Korean high-volume LT center. The graft and patient survival outcomes reflected the early experience of LT in our institution. Our report of the first 1,000 LDLTs performed from December 1994 to June 2005 included 893 adult and 107 pediatric LDLT cases. The most common diagnoses were HBV-associated liver cirrhosis $(80 \%)$ in adult recipients and biliary atresia in pediatric recipients $(63 \%)$. Their 5 -year patient survival rates were $83.2 \%$ in adult recipients and $84.8 \%$ in pediatric recipients [10].

The Organ Transplantation Law was enacted in Korea in February 2000, and the Korean Network for Organ Sharing (KONOS) was established at the same time. This law resulted in a dramatic reduction in the number of DDs due to the strictness of the donation process and the lack of publicity [9]. The number of DDs decreased from 162 in 1999 to 52 in 2000, 52 in 2001, and 36 in 2002. Subsequently, the number of donors gradually increased, with 68 
in 2003, 86 in 2004, 91 in 2005, 141 in 2006, 148 in 2007, and 256 in 2008. The number of patients on the waiting list for DDLT markedly increased during this time period from 620 in 2000 to 3,000 in 2008, with the majority of DD livers allocated to urgent patients [11]. This extreme donor shortage resulted in a greater acceptance of marginal donor livers and a low likelihood of early retransplantation, thereby reducing the graft survival in adults who underwent DDLT.

To cope with the shortage of DDs, adult LDLT became the main type of LT in our institution in 2000-2001, resulting in a marked increase in the number of adult patients undergoing LDLT. The indications for LT were the same in adult LDLT and DDLT recipients. This is the main background reason why the mean MELD score was quite comparable between the adult LDLT and DDLT groups. The mean MELD score in adult LDLT patients at that time was much higher than that in recent years [12].

Concomitantly with the increased demand for LDLT, various standardized techniques of LDLT were also established for the implantation of right liver grafts $[6,13]$. Many innovative surgical techniques were developed, including middle hepatic vein reconstruction using vascular conduit interposition (modified right liver graft), duct-to-duct anastomosis, intraoperative interruption of venous collateral veins, and dual-graft implantation $[6,10,13]$. The development of these techniques, which required trial-and-error processes, might be reflected in the incidence of perioperative mortality in the adult LDLT group. The 3-month patient mortality rate was $4.5 \%$ in the present study, and their causes included early allograft dysfunction, bleeding, infection, and vascular and biliary complications. These outcomes appear to have significantly improved in comparison with the initial experience of LDLT in our institution [14]. Twenty years ago, the surgical techniques for adult LDLT had not matured, but those for DDLT were already established. Consequently, the incidence of surgical complications was higher following LDLT than following DDLT, which was reflected in the 1-year patient survival rates in the present study [10].

Compared with the recent results of adult LDLT, the incidence of HCC recurrence-associated patient mortality was noticeably low, likely because the proportion of LDLT patients with HCC was correspondingly low [8]. The proportion of patients with $\mathrm{HCC}$ has been gradually increasing over time, and HCC has been one of the main indications for adult LDLT at our institution during the last 10 years. Another noticeable difference is the lower proportion of patients with alcoholic liver disease [15], as alcoholic liver disease was not regarded as an ethically eligible indication for LDLT in 2000-2001.

In our previous analysis of the indications of 3,145 LDLTs during a 10-year period from January 2008 to December 2017, common diseases in adult recipients were HBV-associated liver cirrhosis (62.9\%), alcoholic liver disease (16.0\%), hepatitis $C$ virus-associated cirrhosis (6.7\%), acute liver failure $(4.2 \%)$, and other diseases $(5.2 \%)$. The proportion of patients with HBV-associated liver disease gradually decreased, but the proportion of those with alcoholic liver disease increased. HCC was diagnosed in $48.6 \%$ of patients. The mean proportion of patients with HCC was 63.1\% among those with HBV-associated liver disease. In 126 pediatric recipients, the primary diagnoses were biliary atresia $(40.5 \%)$, liver failure of various causes $(29.4 \%)$, metabolic disease (17.5\%), hepatoblastoma (9.5\%), and infectious diseases (3.2\%) [15].

HBV-associated liver cirrhosis was the most common indication of LT in adult patients; thus, posttransplant HBV prophylaxis was an important concern in posttransplant management. Twenty years ago, high-dose hepatitis B immunoglobulin (HBIG) was the choice of HBV prophylaxis in Korea because of absence of effective antiviral agents $[16,17]$. With the development of high-genetic barrier antiviral agents, such as entecavir and tenofovir, combination therapy of low-dose HBIG and an antiviral agent has been the preferred regimen for posttransplant HBV prophylaxis at many institutions in Korea, including our institution $[18,19]$.

The causes of late patient mortality of adult LDLT recipients in the present study were comparable to those of DDLT recipients in Western countries [1-3]. This indicates that the long-term postoperative management should be very similar in adult LDLT and DDLT recipients. However, there were some LDLT recipients who died or underwent retransplantation due to vascular complications, which may be unusual in recipients who have undergone whole-liver DDLT. Life-long surveillance should be recommended for LDLT recipients who undergo endovascular stenting at the hepatic or portal vein $[7,10]$.

Of the 22 patients who underwent pediatric LT, 21 underwent pediatric LDLT and only one underwent DDLT using a whole liver. The marked decrease in the number of DDs during 2000-2001 and the lack of regulations encompassing split LT meant that no patients in the present study underwent pediatric split LT and only one underwent adult split LT [9]. The liver graft allocation policy for pediatric patients changed after the alleviation of strict restric- 
tions for pediatric split LT in 2013 [20]. Although pediatric LDLT was performed earlier than adult LDLT in our institution, the early posttransplant survival outcomes of pediatric LDLT were not superior to those of adult LDLT because many technical factors limited successful pediatric LDLT $[21,22]$. Our recent study presented the long-term outcomes of pediatric LDLT [23]. The 1-year and 5-year patient survival rates were $90.1 \%$ and $81.5 \%$, respectively, in 81 patients who underwent LT between 1994 and 2002; 92.9\% and $92.0 \%$, respectively, in 113 patients who underwent LT between 2003 to 2011 ; and $100 \%$ and $98.6 \%$, respectively, in 93 patients who underwent LT between 2012 to 2020 . Multivariate analyses revealed that a primary diagnosis of acute liver failure, bloodstream infection, posttransplant lymphoproliferative disease, and chronic rejection were negative prognostic indicators for patient survival [23]. Recent technical advances in pediatric LT have led to near-zero perioperative mortality at our institution.

The immunosuppressive regimen and the target trough concentration of immunosuppressive agents at posttransplant 10 or 20 years are matters of concern because of the risk of de novo malignancy and adverse side effects [2426]. Various immunosuppressive regimens have been used during the 20-year period after LT [27], with FK monotherapy, FK-MMF dual therapy, cyclosporine monotherapy, and MMF monotherapy being the most frequent in the present study. In more recent years, everolimus has replaced calcineurin inhibitors or MMF in a small number of our study patients [28]. There is no consensus on the target trough concentration of immunosuppressive agents at posttransplant 10 or 20 years. It is generally recommended to adjust the target trough concentration on a case-by-case basis. We believe that our results regarding the dosage and target trough concentration in patients administrating tacrolimus or cyclosporine monotherapy over 20 years will be used as reference values for personalized adjustment of immunosuppressive agents $[27,28]$.

This study has several limitations. It is a retrospective, single-center study, with small numbers of patients in adult DDLT and pediatric LT groups. This study did not include detailed risk factor analyses for graft and patient survival. Further high-volume multicenter studies are necessary to validate the results of this study.

In conclusion, the present study is the first report of actual 20-year survival data at a Korean high-volume LT center. The graft and patient survival outcomes reflected early experiences with LT at our institution, with long-term outcomes being similar regardless of graft type and pa- tient age. Our results regarding the immunosuppressant dosage and target trough concentration will be used as reference values for personalized adjustment of immunosuppressive agents. High-volume multicenter studies are necessary to assess the long-term outcomes of LT.

\section{ACKNOWLEDGMENTS}

\section{Conflict of Interest}

No potential conflict of interest relevant to this article was reported.

\section{Funding/Support}

This study was supported by research grant from the Korean Society for Transplantation (2022-00-01001-002).

\section{ORCID}

Minjae Kim https://orcid.org/0000-0001-6743-0636

Shin Hwang https://orcid.org/0000-0002-9045-2531

Chul-Soo Ahn https://orcid.org/0000-0002-3844-3646

Deok-Bog Moon https://orcid.org/0000-0002-8209-3540

Tae-Yong $\mathrm{Ha} \quad$ https://orcid.org/0000-0001-9932-0212

Gi-Won Song https://orcid.org/0000-0002-4235-0434

Dong-Hwan Jung https://orcid.org/0000-0001-5984-023X

Gil-Chun Park https://orcid.org/0000-0003-1631-3258

Ki-Hun Kim https://orcid.org/0000-0002-4016-0995 Jung-Man Namgoong

https://orcid.org/0000-0002-9237-7440

Woo-Hyoung Kang https://orcid.org/0000-0002-3734-3352

Young-In Yoon https://orcid.org/0000-0002-9308-0366

Hwui-Dong Cho https://orcid.org/0000-0001-8501-3385

Byeong-Gon Na https://orcid.org/0000-0002-3150-4645

Sang Hoon Kim https://orcid.org/0000-0002-8025-1816

Sung-Gyu Lee https://orcid.org/0000-0001-9161-3491

\section{Author Contributions}

Conceptualization: SH. Data curation: CSA, DBM, TYH, GWS. Formal analysis: DHJ, GCP, KHK, JMN. Methodology: WHK, YIY, HDC, BGN, SHK. Project administration: SH, SGL. Visualization: SH. Writing-original draft: SH, MK. Writingreview \& editing: all authors. 


\section{REFERENCES}

1. Adam R, Karam V, Delvart V, O'Grady J, Mirza D, Klempnauer $\mathrm{J}$, et al. Evolution of indications and results of liver transplantation in Europe: a report from the European Liver Transplant Registry (ELTR). J Hepatol 2012;57:675-88.

2. Kim WR, Lake JR, Smith JM, Skeans MA, Schladt DP, Edwards EB, et al. OPTN/SRTR 2013 annual data report: liver. Am J Transplant 2015;15 Suppl 2:1-28.

3. Dopazo C, Bilbao I, Castells LL, Sapisochin G, Moreiras C, Campos-Varela I, et al. Analysis of adult 20year survivors after liver transplantation. Hepatol Int 2015;9:461-70.

4. Lee SG. Twenty-year survival post-liver transplant: challenges and lessons. Hepatol Int 2015;9:342-5.

5. Firl DJ, Sasaki K, McVey J, Hupertz V, Radhakrishnan K, Fujiki $M$, et al. Improved survival following living donor liver transplantation for pediatric acute liver failure: analysis of 20 years of US National Registry data. Liver Transpl 2019;25:1241-50.

6. Hwang S, Ha TY, Ahn CS, Moon DB, Kim KH, Song GW, et al. Standardized surgical techniques for adult living donor liver transplantation using a modified right lobe graft: a video presentation from bench to reperfusion. Korean J Hepatobiliary Pancreat Surg 2016;20:97-101.

7. Jung D, Hwang S, Ahn C, Moon D, Ha T, Song G, et al. Quilt unification venoplasty of the right hepatic veins enabling double inferior vena cava anastomosis in living donor liver transplantation using a right liver graft. Ann Liver Transplant 2021;1:86-94.

8. Jung D, Hwang S, Song G. Selection criteria of living donor liver transplantation for hepatocellular carcinoma developed in Korean transplant centers. Ann Liver Transplant 2021;1:29-47.

9. Min Sl, Ahn C, Han DJ, Kim SI, Chung SY, Lee SK, et al. To achieve national self-sufficiency: recent progresses in deceased donation in Korea. Transplantation 2015;99:765-70.

10. Hwang S, Lee SG, Lee YJ, Sung KB, Park KM, Kim KH, et al. Lessons learned from 1,000 living donor liver transplantations in a single center: how to make living donations safe. Liver Transpl 2006;12:920-7.

11. Jung $B H, H$ wang $S$, Song GW, Jung $D H, H a T Y$, Park GC, et al. Updated status of deceased-donor liver graft allocation for high-urgency adult patients in a Korean high-volume liver transplantation center. Transplant Proc 2015;47:580-3.
12. Kim SH, Hwang S, Ahn C, Moon D, Ha T, Song G, et al. Absence of influence of the Korean MELD score-based liver allocation system on pretransplant MELD score in patients undergoing living donor liver transplantation. Ann Liver Transplant 2021;1:10-17.

13. Hwang S, Lee SG, Ha TY, Ahn CS, Park KM, Kim KH, et al. Simplified standardized technique for living donor liver transplantation using left liver graft plus caudate lobe. Liver Transpl 2004;10:1398-405.

14. Lee SG, Song GW, Yoon YI. An exceptional series: 5000 living donor liver transplantations at Asan Medical Center, Seoul, Korea. Transplantation 2019;103:173941.

15. Kang SH, Hwang S, Ahn CS, Kim KH, Moon DB, Ha TY, et al. Changes in the indications for living donor liver transplantation: single-institution experience of 3,145 cases over 10 years. Korean J Transplant 2020;34:4754.

16. Hwang S, Lee SG, Ahn CS, Kim KH, Moon DB, Ha TY, et al. Prevention of hepatitis $B$ recurrence after living donor liver transplantation: primary high-dose hepatitis B immunoglobulin monotherapy and rescue antiviral therapy. Liver Transpl 2008;14:770-8.

17. Hwang S, Ahn CS, Song GW, Kim KH, Moon DB, Oh HB, et al. Posttransplantation prophylaxis with primary high-dose hepatitis B immunoglobulin monotherapy and complementary preemptive antiviral add-on. Liver Transpl 2011;17:456-65.

18. Hwang S, Song GW, Chung YK, Ahn CS, Kim KH, Moon $\mathrm{DB}$, et al. Determination of hepatitis $\mathrm{B}$ immunoglobulin infusion interval using pharmacokinetic half-life simulation for posttransplant hepatitis B prophylaxis. J Korean Med Sci 2019;34:e251.

19. Park GC, Hwang S, Kim MS, Jung DH, Song GW, Lee $K W$, et al. Hepatitis B prophylaxis after liver transplantation in Korea: analysis of the KOTRY database. J Korean Med Sci 2020;35:e36.

20. Lee S, Lee SK. Pediatric liver transplantation. J Korean Assoc Pediatr Surg 2013;19:14-21.

21. Hwang S, Namgoong JM. Tailored techniques of graft outflow vein reconstruction in pediatric liver transplantation at Asan Medical Center. Ann Liver Transplant 2021;1:58-70.

22. Hwang S, Namgoong JM. Tailored standardization of portal vein reconstruction for pediatric liver transplantation at Asan Medical Center. Ann Liver Transplant 2021;1:71-78.

23. Oh SH, Jeong IS, Kim DY, Namgoong JM, Jhang WK, 
Park SJ, et al. Recent improvement in survival outcomes and reappraisal of prognostic factors in pediatric living donor liver transplantation. Liver Transpl 2021 Sep 18 [Epub]. https://doi.org/10.1002/lt.26308.

24. Park HW, Hwang S, Ahn CS, Kim KH, Moon DB, Ha TY, et al. De novo malignancies after liver transplantation: incidence comparison with the Korean cancer registry. Transplant Proc 2012;44:802-5.

25. Jung DH, Hwang S, Song GW, Ahn CS, Moon DB, Ha TY, et al. Survival benefit of early cancer detection through regular endoscopic screening for de novo gastric and colorectal cancers in Korean liver transplant recipients. Transplant Proc 2016;48:145-51.

26. Park GC, Hwang S, Ahn CS, Kim KH, Moon DB, Ha TY, et al. Pretransplant hepatic malignancy increases risk of de novo malignancy after liver transplantation. J Korean Med Sci 2020;35:e69.

27. Hwang S, Ahn CS, Kim KH, Moon DB, Ha TY, Song GW, et al. A cross-sectional analysis of long-term immunosuppressive regimens after liver transplantation at Asan Medical Center: increased preference for mycophenolate mofetil. Ann Hepatobiliary Pancreat Surg 2018;22:19-26.

28. Kang S, Hwang S, Ha T, Song G, Jung D, Ahn C, et al. Cross-sectional analysis of immunosuppressive regimens focused on everolimus after liver transplantation in a Korean high-volume transplantation center. Korean J Transplant 2019;33:98-105. 